\title{
A Critical Look at Phenytoin Use for Early Post-Traumatic Seizure Prophylaxis
}

\author{
Sierra Debenham, Behzad Sabit, Rajeet S. Saluja, Julie Lamoureux, \\ Paul Bajsarowicz, Mohammad Maleki, Judith Marcoux
}

\begin{abstract}
Backround: The American Academy of Neurology recommended using phenytoin or carbamazepine to prevent early post-traumatic seizures (PTS) in severe traumatic brain injuries (TBI). In this study, we examined the effects of using phenytoin prophylaxis on mild, moderate, and severe TBIs. There have been no studies looking at compliance rate and side effects of systematic use of phenytoin at a large population scale. The goal of this study is to determine 1) the proportion of TBI patients receiving phenytoin prophylaxis; 2) which parameters decided when to decide administer phenytoin; 3) prophylaxis efficacy and complication rate. Methods: We retrospectively studied all patients admitted with a TBI over a two year-period and collected the following information: age, GCS score, CT-scan Marshall grade, incidence of early PTS, incidence of phenytoin use and time delay, side effects, and incidence of over-dosage or under-dosage. Results: 1008 patients were included. 5.4 \% had early PTS, $2.3 \%$ while on prophylaxis and $3.1 \%$ while not on prophylaxis, $1.9 \%$ before reaching the hospital and $1.2 \%$ prior to phenytoin administration while in hospital. Delay of administration was 5 hours. $64.8 \%$ received prophylaxis and physicians used positive CT scan as the primary decision-making parameter $(\mathrm{p}<.001)$. Compliance with guidelines was $99.7 \%$. Adverse reactions occurred in $0.5 \%$. Levels were drawn in $42.2 \%(52 \%$ therapeutic, $41 \%$ low, $7 \%$ high). Conclusions: Phenytoin is used according to guidelines, with CT scan being the main decision factor for its use. The frequency of early PTS rate is low and side effects are rare. However, earlier administration of phenytoin and adequate levels could further prevent early PTS.
\end{abstract}

RÉSUMÉ: Un regard critique sur l'utilisation précoce de la phénytoïne en prévention des crises convulsives après un traumatisme crânien. Contexte : L'American Academy of Neurology recommande d'utiliser la phénytö̈ne ou la carbamazépine pour prévenir les crises convulsives posttraumatiques (CCPT) précoces dans les traumatismes cránio-cérébraux (TCC) graves. Dans cette étude, nous examinons les effets de l'utilisation de la phénytoïne en prophylaxie dans les TCC légers, modérés et sévères. Aucune étude n'a examiné le taux de fidélité au traitement et les effets secondaires de l'utilisation systématique de la phénytoïne à l'échelle d'une population. Le but de cette étude était de déterminer la proportion de patients ayant subi un TCC qui ont reçu de la phénytoïne en prophylaxie, les paramètres utilisés pour la prescrire, son efficacité prophylactique et le taux de complication. Méthode : Nous avons étudié rétrospectivement tous les patients hospitalisés pour un TCC au cours d'une période de 2 ans et nous avons colligé l'information suivante : l'âge, le score au GCS, la cote de Marshall à la tomodensitometric, l'incidence de CCPT précoces, l'incidence de l'utilisation de la phénytoïne et le délai d'utilisation, les effets secondaires et l'incidence de surdosage ou de sous-dosage. Résultats : 1008 patients ont été inclus dans l'étude, dont 5,4\% avaient eu des CCPT précoces, 2,3\% alors qu'ils prenaient une médication pour prévenir les crises et 3,1\% alors qu'ils n'en prenaient pas, 1,9\% avant l'hospitalisation et 1,2\% avant que la phénytoïne ne soit administrée lors de l'hospitalisation. Le délai d'administration était de 5 heures. Une médication préventive a été administrée chez 64,8\% des patients et les médecins utilisaient une tomodensitométrie positive comme paramètre dans la prise de décision ( $\mathrm{p}<0,001)$. L'adhésion aux lignes directrices était de 99,7\%. Des effets indésirables sont survenus chez $0,5 \%$ des patients. Le taux sanguin a été déterminé chez $42,2 \%$ des patients (thérapeutique chez $52 \%$, faible chez $41 \%$ et élevé chez $7 \%$ ). Conclusions : La phénytö̈ne est utilisée selon les lignes directrices et la tomodensitométrie est le principal facteur pris en compte pour décider de son utilisation. La fréquence de CCPT est faible et les effets secondaires sont rares. Cependant une administration plus précoce de la phénytoïne et des niveaux sanguins adéquats pourraient prévenir davantage les CCPT précoces.

Can. J. Neurol. Sci. 2011; 38: 896-901

The annual incidence of traumatic brain injury (TBI) is estimated at 100-200 per 100,000 of population in Canada. ${ }^{1}$ Approximately 1.7 million people sustain a TBI each year in the United States. ${ }^{2}$ Approximately 275000 of those are serious enough to require hospitalization. Post-traumatic seizures (PTS) are common complications of TBI. Early PTS occurs within seven days of the injury and its incidence varies between 4-25\%, depending on the population studied. ${ }^{3-4}$ Not only are there many side effects associated with early PTS, but they can exacerbate the structural damage to an already injured brain ${ }^{5-6}$ and may contribute to the development of a chronic epileptogenic focus, leading to late $\mathrm{PTS}^{7,8}$ and chronic epilepsy. They may also induce blood pressure changes, hypoxic events ${ }^{9}$, and acute rises

From the Faculty of Medicine (BS), Department of Neurosurgery, Montreal General Hospital (JM, MM), Montreal Neurological Hospital (RSS), McGill University Health Centre; Faculté de Médecine (PB), Médicine Sociale et préventive (JL), Université de Montréal, Montreal, Quebec, Canada; Bringham Young University (SD), Provo, Utah, USA.

Received March 3, 2011. Final Revisions Submitted May 11, 2011.

Correspondence to: Judith Marcoux, Department of Neurosurgery, Montreal General Hospital, McGill University Health Centre, 1650 Cedar ave, room L7-524, Montreal, Quebec, H3G 1A4, Canada. 
in intracranial pressure ${ }^{10}$, also leading to further damage. There are also negative social and economic effects of early PTS (e.g. a patient losing his or her driving privileges for a prolonged period of time).

Phenytoin prophylaxis has been shown to lower the incidence of early PTS from $14.2 \%$ to $3.6 \%$ in one randomized-controlled study. ${ }^{4}$ In 2003, The American Academy of Neurology recommended using phenytoin or carbamazepine to prevent early post-traumatic seizures (PTS) for "severe" traumatic brain injuries. ${ }^{11}$ This recommendation has also been endorsed by the American Association of Neurological Surgeons and the Brain Trauma Foundation (BTF). ${ }^{12}$

While these guidelines on the prophylactic use of phenytoin for PTS were published, clinicians' opinions on the subject still seem to vary. In one paper, clinicians presented with the scenario of an acute epidural hematoma with mass effect agreed that measures such as surgery, fever reduction, early enteral feeding, intensive glucose control, and cerebral perfusion pressuredirected management would all be appropriate. However, antiseizure prophylaxis was of "uncertain appropriateness". ${ }^{13}$ To date, there are no studies reporting information on whether clinical practice differs from scholarly recommendations and whether these differences benefit or harm the quality of patient care. In this study, we examined the effects of using phenytoin prophylaxis on all "severe" TBI, as recommended. The definition of severe TBI used by the American Academy of Neurology is "prolonged loss of consciousness or amnesia, intracranial hematoma or brain contusion on computed tomogram (CT) scan, and/or depressed skull fracture". The aims of this study are to determine: 1) the proportion of admitted TBI patients at a large population scale that received phenytoin prophylaxis; 2) which parameters physicians used to decide when to administer phenytoin; 3) the efficacy and complication rate associated with adhering to current phenytoin prophylaxis guidelines.

\section{Methods}

\section{Patient population}

The Montreal General Hospital (MGH), part of the McGill University Health Centre (MUHC), is one of only three adult tertiary (level 1) trauma centres serving the province of Quebec, Canada, which has a population of almost eight million people. The Montreal General Hospital TBI Database was used to identify all patients with a diagnosis of TBI admitted between April 1st, 2007 and March 31st, 2009. We performed a retrospective study of early post-traumatic seizure prophylaxis in the 1078 consecutive cases of TBI identified during this twoyear period. The MUHC Ethics Review Board and the Director of Professional Services approved this study and the informed consent requirement was waived.

\section{Exclusion Criteria}

Patients were excluded from data collection and/or analysis for the following reasons: (1) the TBI occurred more than seven days prior to admission; (2) upon review there was no TBI; and (3) charts were missing or incomplete.

\section{Phenytoin administration}

Phenytoin was administered, in most instances, intravenously

with a loading dose of $17 \mathrm{mg} / \mathrm{kg}$ intravenous infusion over 30 to 60 minutes, followed by a maintenance dose of $100 \mathrm{mg}$ given three times daily, either intravenously or orally for a total of seven days. On occasion, when patients were relatively well and did not have continuous cardiac monitoring, a dose of $300 \mathrm{mg}$ orally was given at every six hours for a total of three doses (900mg), followed by the same maintenance dose described above.

\section{Data Collected}

The variables of interest that were collected included: age, Glasgow Coma Scale (GCS) score ${ }^{14}$ after initial resuscitation, incidence of early PTS and the timing in regard to hospital arrival and beginning of prophylaxis; incidence of phenytoin use and time delay from hospital arrival; side effects associated with the prophylaxis used; incidence of phenytoin over- or underdosage. Therapeutic dosage was defined according to two criteria: 1) a phenytoin serum level between 40 and $80 \mu \mathrm{mol} / \mathrm{L}$ within seven days post-trauma and 2) if an albumin level was recorded at the same time as the phenytoin level, a corrected level was calculated according to the albumin level. A previous history of an underlying seizure disorder was also recorded. A diagnosis of seizure was made when reported as such in the

Table 1: Marshall CT Classification for Head Injury ${ }^{15}$
Category
Definition

Diffuse Injury I

no visible intracranial pathology seen on CT

Diffuse Injury II

cisterns are present with midline shift $0-5 \mathrm{~mm}$ and/or lesion densities present no high- or mixed-density lesion > $25 \mathrm{~mL}$; may include bone fragments and foreign bodies

Diffuse Injury III cisterns compressed or absent with midline shift $0-5 \mathrm{~mm}$, no high- or mixed-density lesion $>25 \mathrm{~mL}$

Diffuse Injury IV

midline shift $>5 \mathrm{~mm}$, no high- or mixed-density lesion $>25 \mathrm{~mL}$

Diffuse Injury $\mathrm{V}$

(Evacuated Mass Lesion)

Diffuse Injury VI

(Non- Evacuated Mass Lesion)

$\mathrm{CT}=$ computed tomogram 


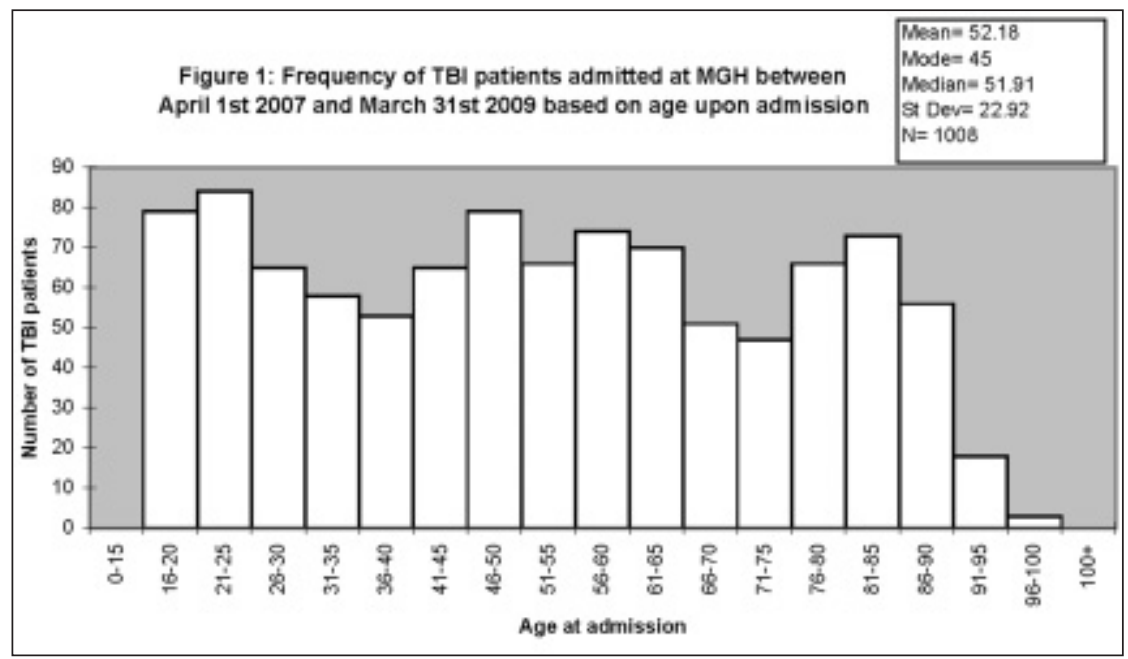

Figure 1: Frequency of traumatic brain injury (TBI) patients admitted during the two year period, based on age at admission. St DEV= standard deviation; $N=$ number of patients

medical charts, according to doctor's and nurse's notes describing the seizure (partial motor seizure, generalized tonicoclonic, secondary generalized, or partial complex seizure) or by electro-encephalogram (EEG) monitoring. An EEG was done when a seizure was suspected: in sudden rises of intracranial pressure, in unexplained decreased level of consciousness, in poor neurological progression, for eye flickering or twitching seen in the intensive care unit (ICU).

Computed tomogram scan images were also reviewed and scored between 1 and 6, according to a modified Marshall grade score $^{15-16}$ (see Table1). For patients who did not have a CT-scan at our institution, but only at an outside institution, the radiological report was used to determine the Marshall grade score, if the images were not available.

\section{Statistics}

Descriptive statistics were reported for all variables as means and standard deviations for numerical variables, and percentages for categorical data. Analyses were done using the statistical computer software program PASW Statistics 17.0 (SPSS, Chicago, IL). Bivariate associations between the administration of phenytoin and subject characteristics were assessed through ttests or chi-square tests, depending on the nature of the variables. In order to determine which factors were more significantly associated with the decision to administer phenytoin, we used a backward logistic regression to determine the relationship between baseline characteristics and the administration of phenytoin. Statistical significance was set at $\mathrm{p}<0.05$.

\section{RESULTS}

\section{Patient characteristics}

The MGH TBI database contained 1077 charts coded as "TBI". Fifty patients had either no TBI or a TBI that had occurred more than seven days prior to admission and were therefore excluded. Another twenty patients were excluded due to missing or incomplete charts. One patient presented twice with an acute TBI during the two-year span of the study. Therefore, there were 1007 patients included with 1008 entries.

The average $( \pm \mathrm{SD})$ age of the subjects was $52.16 \pm 22.30$ years of age, ranging from 16 to 97 (see Figure 1). The initial GCS varied between 3 and 15 with an average $( \pm$ SD) of $12.50 \pm$ 3.81. Almost $50 \%$ of the subjects had an initial GCS of 15 . There were 10 subjects with missing GCS scores. The median was $14.18 \%$ of the subjects had a severe TBI (GCS 3-8), less than $10 \%$ had a moderate TBI (GCS 9-12) and the remaining (about 73\%) had a mild TBI (GCS 13-15) (see Figure 2).

Sixty-nine percent of the sample (697 out of 1007, 1 missing value) had findings of acute intracranial injury on the CT-scan (see Table 2). All patients with reports from outside institutions and no CT-scan images available had normal findings (Marshall grade 1).

\section{Prophylaxis administration}

Six hundred and fifty-three $(64.8 \%)$ subjects were administered phenytoin as a preventive agent. Thirty-three (3.3\%) patients had a diagnosis of seizure disorder prior to admission and seventeen (1.7\%) patients were already on antiseizure medication and were continued on their medication instead of phenytoin. Bivariately, the variables associated with the prophylaxis use of phenytoin were age, positive CT findings, the Marshall grade and the initial GCS (see Table 3). When considering only those variables in the backward dichotomous logistic regression, two factors were significant in explaining this use of phenytoin: positive CT findings and a Marshall grade of 4 or more. A patient with positive traumatic findings on the CT scan was 22.6 times more likely (95\% CI $=[15.589 ; 32.164]$ ) to receive phenytoin than if the CT scan was normal. Also, a patient with a Marshall grade of 4 or more on CT scan was 3.4 times more likely $(95 \% \mathrm{CI}=[1.672 ; 6.916])$ to receive phenytoin prophylaxis. The effect of age and GCS were not statistically significant once CT findings and Marshall scores were taken into consideration. 
Table 2: Frequency of Marshall CT score in our patient population

\begin{tabular}{c|c|c}
\hline \multicolumn{1}{|c|}{ Marshall } & \multicolumn{1}{c}{ Number of } & Percentage \\
CT score & patients & \\
\hline 1 & 310 & 30.8 \\
2 & 522 & 51.8 \\
3 & 14 & 1.4 \\
4 & 10 & 1.0 \\
5 & 107 & 10.6 \\
6 & 45 & 4.5 \\
\hline
\end{tabular}

\section{Timing of administration and levels}

In 504 patients we could calculate the exact time delay between admission and phenytoin load; the mean was 299.6 minutes $(\mathrm{SD}=282.6)$. In $266(42.2 \%)$ patients a phenytoin serum level was drawn at least once during the first seven days. One hundred and ten $(41.4 \%)$ had at least one adjusted phenytoin level too low, 18 (7\%) had one level too high, 138 (51.9\%) had therapeutic levels.

\section{Post-traumatic seizure incidence}

A total of $54(5.4 \%)$ patients had early PTS. Patients who developed early PTS tended to be somewhat older (average 59.7 years) and to have a lower GCS score (10.4) but these differences were not statistically significant. Of note is that 16 (29.6\%) patients with early PTS had a presenting GCS of 15 , and another six $(11.1 \%)$ had a GCS of 13 or 14 . Nineteen $(35.2 \%)$ patients had a GCS of 8 or less. Patients with PTS had a higher Marshall grade score (3.2 compared to 2.2). However 10 had a normal CT-scan. Only two patients with early PTS had a depressed skull fracture and penetrating head injury. Nearly half (26 patients) however had an acute subdural hematoma, and $15(27.8 \%)$ had intracerebral contusions or hematomas.

\section{Post-traumatic seizure timing and prophylaxis}

Of the 54 patients with PTS, 23
(2.3\%) had received phenytoin prophylaxis, while $31(3.1 \%)$ had a seizure while not on phenytoin. Nineteen $(1.9 \%)$ of these 31 patients had immediate seizures prior to reaching the hospital; another $12(1.2 \%)$ had a seizure prior to phenytoin administration in the hospital. Of these 12 patients, five had their seizure in an outside hospital, prior to being transferred to our tertiary care center. The other seven patients had their seizure at $5,7,9,24,259,700$ and 1440 minutes after arrival to our institution respectively. The latest one had a GCS 15 on arrival and a normal CT-scan, and was therefore not given phenytoin prophylaxis. Figure 3 gives a breakdown of the timing of seizures. A total of 78 patients had EEG testing done to confirm or infirm seizures. Twenty-seven patients had continuous EEG monitoring done. Three patients had seizures diagnosed on EEG, including one intra-operative seizure.

Nineteen of the 23 patients who had seizures while on prophylaxis had a phenytoin serum level measured while on treatment. Of these patients, nine had a therapeutic level, seven had a low level, and two had a high level.

\section{Phenytoin-related side effects}

A total of five patients, or $0.8 \%$ of patients who received phenytoin, had adverse reactions. The side effects were as follows: one patient had bradycardia recorded while receiving an intravenous loading dose, one patient developed face and trunk redness, one patient complained of skin itchiness without a rash, and two patients developed elevated liver enzymes. Four of these five patients did not have their phenytoin levels tested, but the only patient tested had a therapeutic level of phenytoin.

\section{Compliance with guidelines}

Of the 355 patients who did not receive phenytoin prophylaxis, only three patients seemed to have met criteria for prophylaxis upon review of their charts. One patient had a GCS score of seven, while two patients had significant findings on

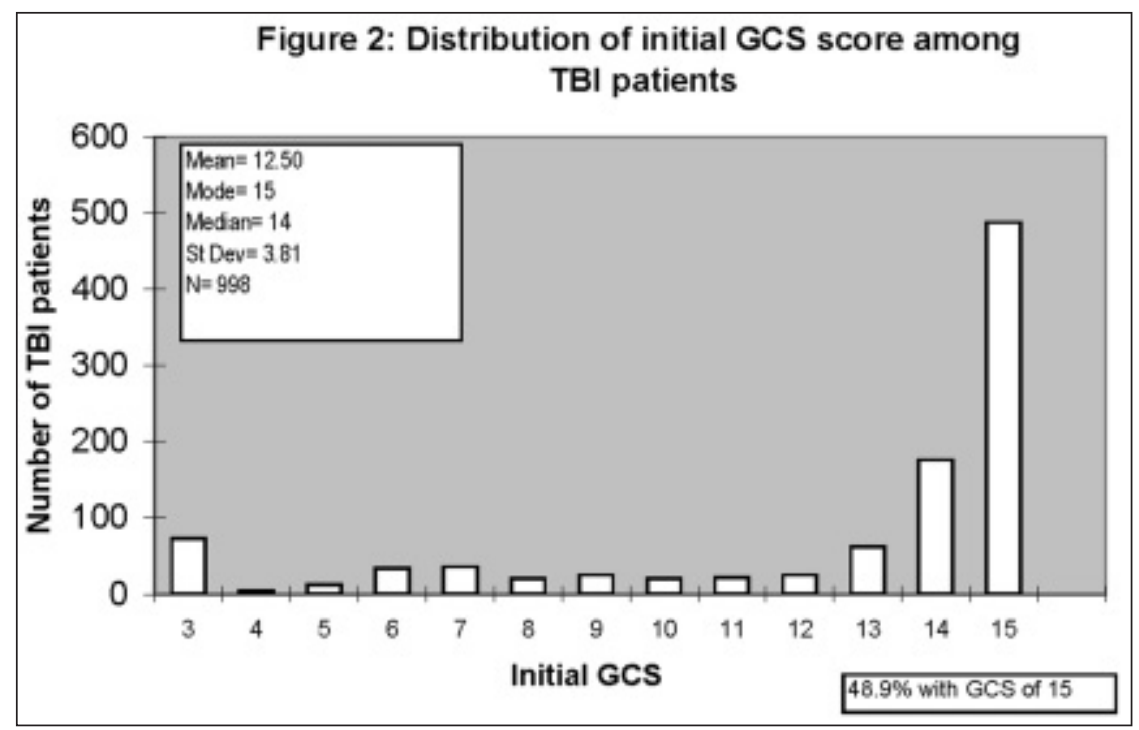

Figure 2: Distribution of initial Glasgow Coma Scale score (GCS) among patients. TBI = traumatic brain injury; St Dev= standard deviation; $N=$ number of patients 


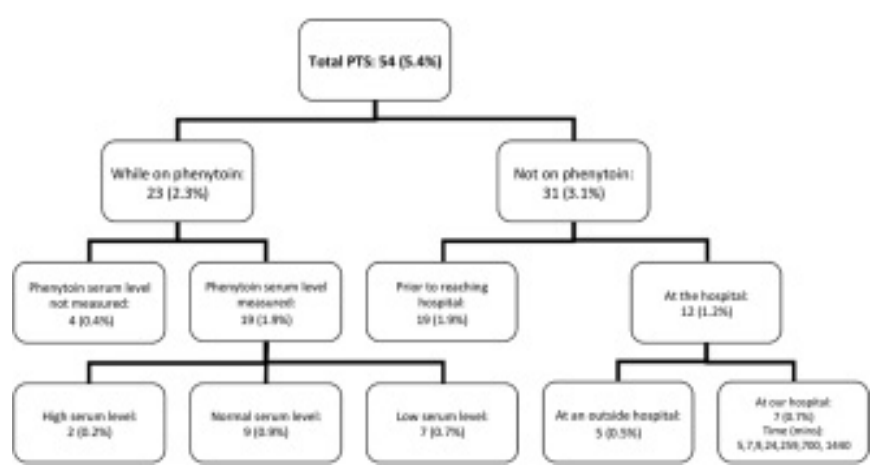

Figure 3: Representation of post-traumatic seizure incidence according to prophylaxis or not and timing. $P T S=$ post-traumatic seizure; mins = minutes.

their CT-scan; one had a significant subdural haematoma and the other one had multiple intra-cerebral contusions. This represents $0.03 \%$ of the total patient population studied, or a compliance rate of $99.7 \%$ with the guidelines.

\section{Discussion}

Compliance with the American Academy of Neurology and the Brain Trauma Foundation guidelines might contribute to a low rate of early PTS, with an incidence of $2.3 \%$ in this series. This is comparable with the rate reported by Temkin et al. ${ }^{4}$ The compliance rate was very high in our tertiary care center, reaching $99.7 \%$. This high compliance rate may be due to two factors: 1) TBI patients are likely to be seen by emergency physicians, the trauma team, a neurosurgeon, and also often by an intensivist, which increases the likelihood of at least one physician prescribing phenytoin prophylaxis when indicated; 2) the institution has a protocol-driven practice; therefore, upon admission to an intensive care unit - at the very latest - phenytoin is prescribed and administered. The compliance rate may not be as high in non-tertiary centers. However, since in an organized trauma system, almost all victims of significant TBI are either directly transported to a tertiary care center after their injury or quickly transferred after brief stabilisation in primary or secondary centers ${ }^{17}$, most patients that meet criteria for PTS prophylaxis will receive it with a relatively short delay postinjury.

The primary decision-making parameter was the CT-scan findings, which is likely to cover a significant cause of PTS. Indeed, the amount of focal tissue destruction is the most important factor in predicting the development of early and late post-traumatic seizures. ${ }^{18}$ The degree of injury on CT-scan, as measured by Marshall grade score, followed. Patients receiving phenytoin were significantly older, but this could be explained by the fact that older age is a risk factor for intracranial findings after a head injury. ${ }^{19-23}$ Indeed, when adjusting for CT findings, age was not an independent factor predicting the use of phenytoin. When we compared the group of patients who had early PTS to the entire patient population, age was not a factor for developing PTS, nor was GCS, with more mild (GCS 13-14) than severe TBI (GCS 8 or less). However, those patients who had PTS had also more severe injuries on CT-scan. This finding seems to support our current practice.

We encountered a low incidence of side effects, all of which were mild. Phenytoin use can be associated with many side effects, some being potentially fatal. Some potential side effects affecting the central nervous system such as dizziness, sedation, diplopia and ataxia may be mistaken for symptoms related to the brain injury and therefore overlooked. Other manifestations such as hypotension and arrhythmias should however be easily detected while patients are being monitored during and shortly after the initial loading dose of phenytoin. Side effects related to chronic use of phenytoin, such as gingival hyperplasia, hematologic abnormalities, and teratogenicity manifest with prolonged use of the drug and were not seen in this series. Only one mild case of potential allergic reaction (skin rash) was seen.

In this study, we found that we clearly did not adequately measure phenytoin levels in all patients. Furthermore, we found that almost half of patients who were tested had at least one nontherapeutic phenytoin level within the first week. We noted that in the 23 patients under prophylaxis who did have early PTS, seven had abnormally low levels, and an additional four had no level tested. This means that up to eleven cases (48\%) of early PTS on prophylaxis may have been prevented if levels had been adequately monitored and adjusted. The low rate of phenytoin levels monitoring may be partially explained by the fact that a proportion of the patients may not have been hospitalized long enough to be tested.

We found that we had an average of five hours in delay between patient admission and phenytoin administration in this study. However, since the peak of early PTS is within 48 hours of the injury ${ }^{24}$, the majority occurring within 24 hours post injury $^{25}$, prophylaxis should be administered early. Moreover, it is believed that the epileptogenic process leading to posttraumatic seizure begins at the time of injury. ${ }^{9}$ Prophylaxis should therefore be administered as early as possible, some recommending even within one hour of the trauma itself. ${ }^{10}$ Indeed, in our series, 19 patients seized shortly after the injury, another five while at another institution and another three early PTS occurred within ten minutes of admission to our institution.

Table 3: Patients characteristics according to the administration of prophylaxis or not

\begin{tabular}{c|c||c|c}
\hline Factor & Prophylaxis given & $\begin{array}{c}\text { Prophylaxis not } \\
\text { given }\end{array}$ & p value \\
\hline Mean Age & $55.0 \pm 22.3$ & $46.9 \pm 21.3$ & $<0.001$ \\
\hline CT + & $85.8 \%$ & $17.7 \%$ & $<0.001$ \\
\hline $\begin{array}{c}\text { Marshall } \\
\text { grade }\end{array}$ & $2.78 \pm 1.44$ & $1.39 \pm 0.85$ & $<0.001$ \\
\hline GCS & $12.07 \pm 3.96$ & $13.29 \pm 3.40$ & $<0.001$ \\
\hline
\end{tabular}


One more had PTS 24 minutes after admission. Many of these very early PTS are difficult to prevent.

While administering phenytoin as early as possible postinjury will prevent early PTS and may prevent secondary damage, recent studies on rat populations suggest that indiscriminate phenytoin use may cause harm ${ }^{26}$. Also, even when using phenytoin according to recommendations, preventing early PTS may have limited effect on overall patient outcome and late PTS incidence.

The limitations of this chart review include its reliance on the written records (i.e., progress notes and discharge summaries) of multiple individuals, including medical staff physicians, residents, and nurses, each with their different levels of attention to detail. ${ }^{27}$ Often the exact timing of administration of phenytoin could not be found. Furthermore, our reported incidences of seizures may not accurately reflect true epileptic activity, as EEG was continuously recorded in only a few patients, and other events may be misinterpreted as seizures. In addition, this population contains mainly patients with "mild" TBI, which might lower the frequency of PTS. Twenty patients had to be excluded, either because charts could not be localized, or because some components of the charts were missing.

\section{Conclusions}

A high rate of compliance with guidelines for phenytoin administration following TBI was likely responsible for the low incidence of early PTS observed in our institution. In our study the low incidence of short-term side-effects appeared to justify the use of phenytoin for seizure prophylaxis in a large population group. At least one level should be drawn during the first seven days.

\section{ACKNOWLEDGMENTS}

The authors thank Mrs. Johanne Prud'homme from the Trauma Registry of the Montreal General Hospital for quickly providing the necessary data. We also thank Mrs. Mitra Feyz, Director of the Traumatic Brain Injury Program, and Mrs. Céline Rainville, for providing the data from the Traumatic Brain Injury data bank and for their continuous support.

\section{REFERENCES}

1. Ministry of Health Services and Ministry of Health Planning. Guidelines for planning brain injury services and supports in British Columbia. Victoria, BC. 2002 January. Available from: http://www.health.gov.bc.ca/library/publications/year/2002/MH A Brain Injury Guidelines.pdf

2. Centers for Disease Control and Prevention.gov[homepage on the Internet]. Centers for Disease Control and Prevention 1600 Clifton Rd. Atlanta, GA 30333, USA [updated 2011 May 5; reviewed 2010 March 8]. Available from: http://www.cdc.gov/ ncipc/tbi/TBI.htm

3. Agrawal A, Timothy J, Pandit L, Manju M. Post-traumatic epilepsy: an overview. Clin Neurol Neurosur. 2006;108:433-9.

4. Temkin NR, Dikmen SS, Wilensky AJ, Keihm J, Chabal S, Winn HR. A randomized, double-blind study of phenytoin for the prevention of post-traumatic seizures. N Engl J Med. 1990;323: 497-502.

5. Schierhout G, Roberts I. Anti-epileptic drugs for preventing seizures following acute traumatic brain injury. Cochrane DB Syst Rev. 2001;CD000173. Review.
6. Bao YH, Bramlett HM, Atkins CM, et al. Post-traumatic seizures exacerbate histopathological damage after fluid-percussion brain injury. J Neurotraum. 2011;28:35-42.

7. Weiss GH, Feeney DM, Caveness WF, et al. Prognostic factors for the occurrence of posttraumatic epilepsy. Arch Neurol. 1983;40: $7-10$.

8. Asikainen I, Kaste M, Sarna S. Early and late posttraumatic seizures in traumatic brain injury rehabilitation patients: brain injury factors causing late seizures and influence of seizures on long-term outcome. Epilepsia. 1999;40:584-9.

9. Iudice A, Murri L. Pharmacological prophylaxis of post-traumatic epilepsy. Drugs. 2000;59:1091-9.

10. Teasell R, Bayona N, Lippert C, Villamere J, Hellings C. Posttraumatic seizure disorder following acquired brain injury. Brain Injury. 2007;21:201-14.

11. Chang BS, Lowenstein DH. Practice parameter: Antiepileptic drug prophylaxis in severe traumatic brain injury: report of the quality standards subcommittee of the American Academy of Neurology. Neurology. 2003;60:10-16.

12. Brain Trauma Foundation Guidelines. Role of antiseizure prophylaxis following head injury. J Neurotraum. 2007;suppl 1: S83-S6.

13. Jacka MJ, Zygun D. Survey of management of severe head injury in Canada. Can J Neurol Sci. 2007;34(3):307-12.

14. Teasdale G. Jennett B. Assessment of coma and impaired consciousness: a practical scale. Lancet. 1974;13:81-4.

15. Marshall LF, Eisenberg HM, Jane JA. A new classification of head injury based on computerized tomography. J Neurosurg. 1991; 75:S14-20.

16. Marshall LF, Marshall SB, Klauber MR, et al. The diagnosis of head injury requires a classification based on computed axial tomography. J Neurotraum. 1992;9:S287-92.

17. Liberman M, Mulder DS, Lavoie A, Sampalis JS. Implementation of a trauma care system: evolution through evaluation. J Traum. 2004;56:1330-5.

18. Englander J, Bushnik T, Duong TT, et al. Analyzing risk factors for late posttraumatic seizures: a prospective, multicenter investigation. Arch Phys Med Rehabil. 2003;84:365-73.

19. Saboori M, Ahmadi J, Farajzadegan Z. Indications for brain CT scan in patients with minor head injury. Clin Neurol Neurosurg. 2007;109:399-405

20. Franko J, Kish KJ, O'Connell BG, Subramanian S, Yuschak JV. Advanced age and preinjury warfarin anticoagulation increase the risk of mortality after head trauma. J Traum. 2006;61: 107-10.

21. Borczuk P. Predictors of intracranial injury in patients with mild head trauma. Ann Emerg Med. 1995;25:731-6.

22. Schynoll W, Overton D, Krome R, et al. A prospective study to identify high-yield criteria associated with acute intracranial computed tomography findings in head-injured patients. Am J Emerg Med. 1993;11:321-6.

23. Gutman MB, Moulton RJ, Sullivan I, Hotz G, Tucker WS, Muller PJ. Risk factors predicting operable intracranial hematomas in head injury. J Neurosurg. 1992;77:9-14.

24. Grisar T, Bottin P, Borchgrave d'Alténa V, et al. Prophylaxis of the epilepsies: should anti-epileptic drugs be used for preventing seizures after acute brain injury? Acta Neurol Belg. 2005;105: 5-13.

25. Khan AA, Banerjee A. The role of prophylactic anticonvulsants in moderate to severe head injury. Int J Emerg Med. 2010;3: 187-91.

26. Darrah SD, Chuang J, Mohler LM, et al. Dilantin therapy in an experimental model of traumatic brain injury: effects of limited versus daily treatment on neurological and behavioral recovery. J Neurotraum. 2011;28:43-55.

27. Hess DR. Retrospective studies and chart reviews. Respir Care. 2004;49:1171-4 